Fourth International Conference on Sustainable Construction Materials and Technologies http://www.claisse.info/Proceedings.htm

SCMT4

Las Vegas, USA, August 7-11, 2016

\title{
Chloride Penetration of Concrete Elements Rehabilitated with Sustainable Composites: Material Characterization and High- Fidelity Sensing
}

\author{
Ibrahim Bumadian ${ }^{1 a}$, Salem Egdaire ${ }^{1 b}$, Deepak Kumar ${ }^{1 c}$, Yiming Deng ${ }^{1 d}$, and \\ Yail J. Kim ${ }^{1 e}$ \\ ${ }^{1}$ Department of Civil Engineering and Department of Electrical Engineering; University of \\ Colorado Denver-Denver, CO,USA. ${ }^{1 a}$ Email: <ibrahim.bumadian@ucdenver.edu>, ${ }^{1 b}$ Email: \\ $<$ salem.egdaire@ucdenver.edu>, ${ }^{1 c}$ Email: <Deepak.kumar@ucdenver.edu>, \\ ${ }^{1 d}$ Email: <yiming.deng@ucdenver.edu>, ${ }^{1 e}$ Email:<jimmy.kim@ucdenver.edu>
}

\begin{abstract}
An experimental program is conducted to study chloride penetration characteristics of concrete partially or fully bonded with carbon fiber reinforced polymer (CFRP) composite sheets in an aggressive service circumstance. A standard test protocol for electrical indication of concrete's ability to resist chloride ion penetration (ASTM C1202) is employed to examine the mobility of chlorides inside the concrete. The ingress of chlorides is influenced by CFRP-coverage ratios such that the current flow and resistivity are reduced with an increasing coverage ratio. The concept of near-field microwave microscopy is exploited to evaluate its potential for scanning CFRP-bonded concrete including chlorides.
\end{abstract}

\section{INTRODUCTION}

Aggressive environmental attributes are often considered to be a critical contributor leading to the deterioration of existing highway bridges. Structural members located in cold regions or marine environments are particularly vulnerable to corrosion damage because of chloride penetration and their performance may be degraded accordingly. Expenses executed by transportation agencies to maintain acceptable conditions of constructed structural members are tremendous [ASCE 2013]. Chloride ingress into bridge components such as reinforced concrete decks is thus a crucial subject that requires a significant understanding to extend the longevity of constructed bridges. Diffusion is recognized as an effective mechanism when explaining the mobility of chlorides inside concrete [Neville 2005]. Benz [2007] proposed a computer model to predict the degree of chloride penetration in concrete with due considerations on electrical conduction, conductivity, and ionic diffusion. Mohamed et al. [2014] studied the permeability of chlorides in various types of concrete using salt ponding and rapid chloride permeability methods. Kong and Ge [2015] examined the effect of aggregate size on the permeability of chlorides and found that i) such an effect was noticeable on the porosity of concrete and ii) the aggregate size should be considered when 
estimating chloride permeability. Liu et al. [2015] accounted for a method concerning electrical resistivity to estimate the coefficient of chloride-diffusion through concrete.

Carbon fiber reinforced polymer (CFRP) composites have successfully been used for upgrading deteriorated reinforced or prestressed concrete members that suffered from mechanical or environmental damage. Some benefits of using CFRP encompass light weight and high strength and modulus, noncorrosive nature, durability, and prompt installation [ACI 2008]. Remarkable advances have been achieved since CFRP materials were introduced to the civil structural community in the 1990's [ACI 2007]. As is for the case of conventional structural members, the behavior of CFRP-strengthened ones is also affected by corrosion damage. Extent research results as to the corrosion of the members are dedicated to structural investigations [Bousias et al. 2004; Soudki et al. 2007], while a fundamental understanding of chloride penetration in concrete is insufficient; for example, how CFRP influences a chloride ingress mechanism in a strengthened member. This research reports a test program examining the mobility of chlorides in CFRPbonded concrete so that the role of CFRP can be understood in a corrosive service condition. Another interest of the present/ongoing study is to assess the feasibility of a high-fidelity sensing technique in tandem with near-field microwave microscopy on characterizing the ingress of chloride into CFRP-bonded concrete. Preliminary scanning results are reported to evaluate the potential of such a method for sensing CFRP-concrete assemblies in a chloride environment.

\section{RESEARCH SIGNIFICANCE}

Despite the relatively long history of CFRP-strengthening over two decades, the effect of chlorides on the performance of strengthened structures was not well documented, particularly from diffusivity standpoints. The most widely used method to examine the extent of chloride ingress in concrete is the rapid chloride permeability test specified in ASTM C1202 (Standard test method for electrical indication of concrete's ability to resist chloride ion penetration, ASTM 2012). In this research program, CFRP-bonded concrete was tested in accordance with ASTM C1202 to characterize the contribution of CFRP sheets when subjected to detrimental chlorides. Preliminary sensing investigations into chloride-impregnated concrete bonded with CFRP are also discussed.

\section{CHLORIDE PERMEABILITY TEST}

Materials. Typical concrete cylinders having a dimension of $\phi 100 \mathrm{~mm}$ and $200 \mathrm{~mm}$ long were prepared with a mixture design of portland cement $\left(352 \mathrm{~kg} / \mathrm{m}^{3}\right)$, sand $\left(480 \mathrm{~kg} / \mathrm{m}^{3}\right)$, gravel $\left(865 \mathrm{~kg} / \mathrm{m}^{3}\right)$, and water $\left(160 \mathrm{~kg} / \mathrm{m}^{3}\right)$. The 28 -day cured cylinders were sawed to produce $50 \mathrm{~mm}$ thick concrete disks (figure 1). After slicing the cylinders, the surface was covered by CFRP sheets and an epoxy adhesive at variable coverage ratios from $25 \%$ to $100 \%$ of the surface area, as shown in figure 2 . Each specimen had an identification code illustrating the degree of coverage: S- $0 \%, \mathrm{~S}-25 \%, \mathrm{~S}-$

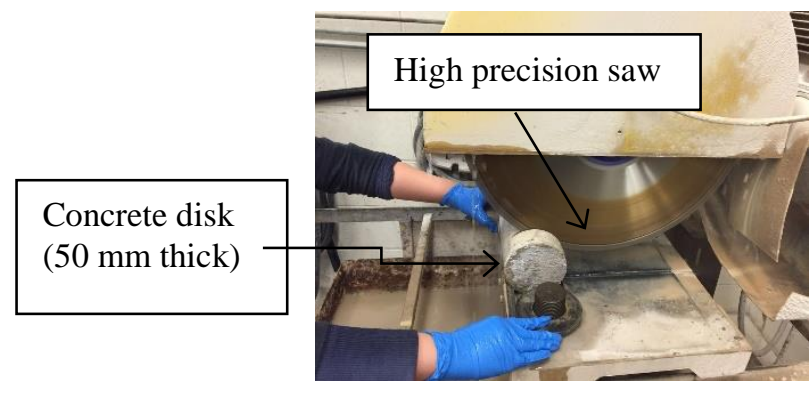

Figure 1. Slicing concrete cylinder

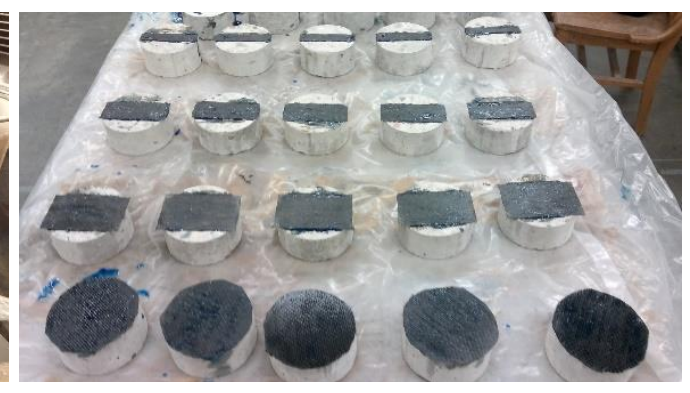

Figure 2. CFRP-covered concrete disk 
$50 \%$, and $\mathrm{S}-100 \%$ for the $0 \%, 25 \%, 50 \%$, and $100 \%$ coverage rations, respectively. The unidirectional CFRP had the following engineering properties: ultimate strength $=3800 \mathrm{MPa}$, tensile modulus $=227 \mathrm{GPa}$, and equivalent thickness $=0.165 \mathrm{~mm}$. The bonding agent was comprised of two parts such as a resin and a hardener and had a strength of $55 \mathrm{MPa}$ along with an elastic modulus of $3 \mathrm{GPa}$.

Rapid chloride permeability test. The cured CFRP-bonded concrete disks were put in a vacuum chamber filled with water for an hour and remained in water for 18 hours, following the procedures of ASTM C1202, as shown in figure 3. After completing the vacuum saturation process, the specimen was located in between two test cells containing sodium chloride $(3 \%)$ and sodium hydroxide $(0.3 \mathrm{M})$ solutions that were connected with electric wires (figure 4), including a 60 volt potential being applied for 6 hours. To address experimental uncertainty, the responses of five specimens were measured per coveragecategory and their average values were analyzed.

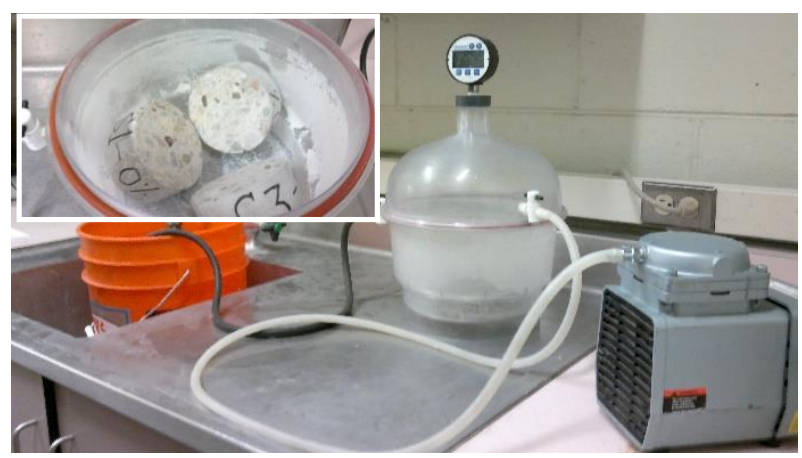

Figure 3. Specimens and vacuum chamber

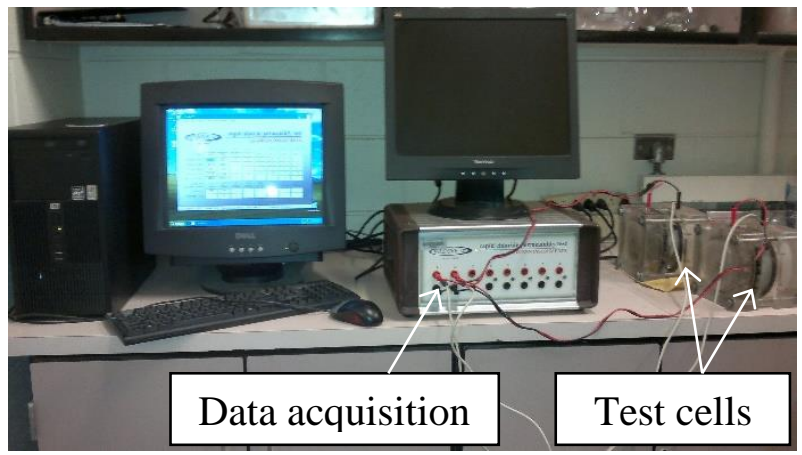

Figure 4. Rapid chloride permeability test

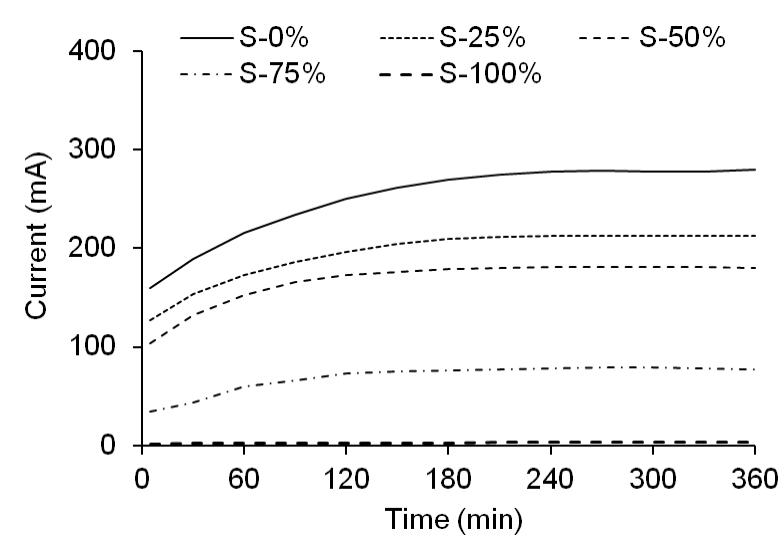

Figure 5. Current-time response

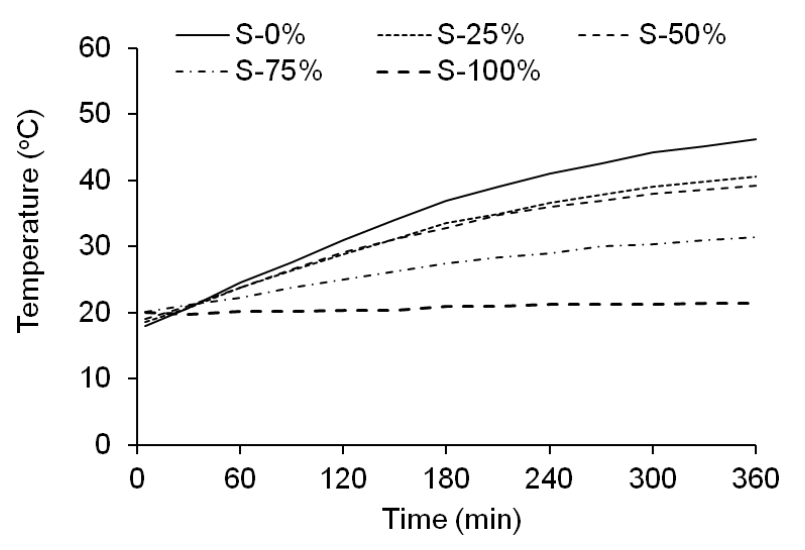

Figure 6. Temperature in $\mathrm{NaCl}$ reservoir

\section{EXPERIMENTAL RESULTS}

Current variation. Figure 5 depicts the variation of electric current with time. All specimens, except for the fully covered S-100\% category, showed a gradually increasing trend followed by stabilized current values. This observation indicates that the pores of the concrete were saturated. The more the concrete was covered, the earlier the saturation time became. 
Temperature increase. With an increase in electric current discussed above, resistive heating took place in the sodium chloride cell (figure 6). It can be explained by the fact that the electric energy transported from one cell to another was converted to thermal energy. A noticeable increase in temperature of $28^{\circ} \mathrm{C}$ was measured for the uncovered concrete (S-0\%), implying that the thermal energy in the concrete was substantial.

Resistivity. The resistivity of the concrete specimens was calculated using Eq. 1 and shown in figure 7:

$$
\rho=R \frac{A}{l}
$$

in which $\rho$ is the resistivity; $R$ is the electrical resistance; and $A$ and $l$ are the cross-sectional area and depth of the disk, respectively. According to CEB-192 (CEB 1989), resistivity values can be used to conjecture the risk of corrosion damage in reinforced concrete members: $\rho>200 \Omega \mathrm{m}$ (negligible), $200 \Omega \mathrm{m}>\rho>$ $100 \Omega \mathrm{m}$ (low), $100 \Omega \mathrm{m}>\rho>50 \Omega \mathrm{m}$ (high), and $50 \Omega \mathrm{m}>\rho$ (very high). The $\mathrm{S}-100 \%$ specimens exhibited an average of $3013 \Omega \mathrm{m}$ at 360 minutes, while the S-75\% ones showed $121 \Omega \mathrm{m}$. Other disks having a coverage ratio of $50 \%$ to $0 \%$ revealed significantly lower resistivity than the previous counterparts. This fact implies that CFRP sheets almost completely controlled the possibility of corrosion damage within the covered regions

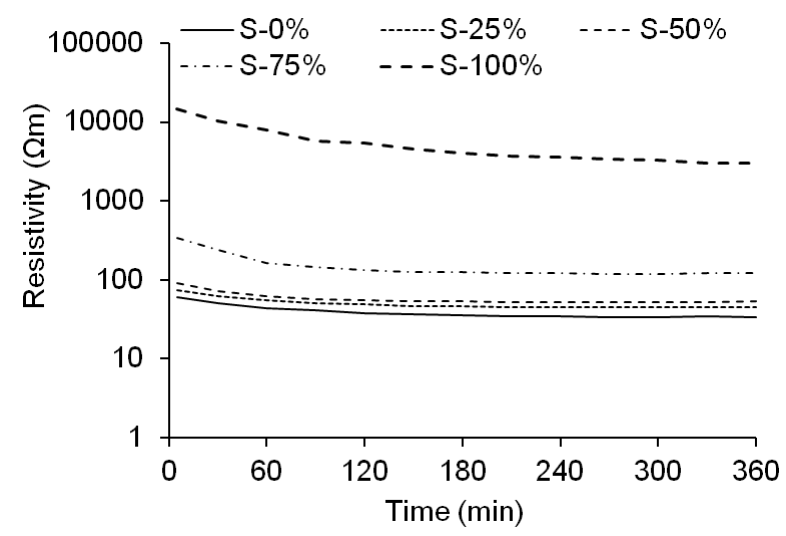

Figure 7. Resistivity

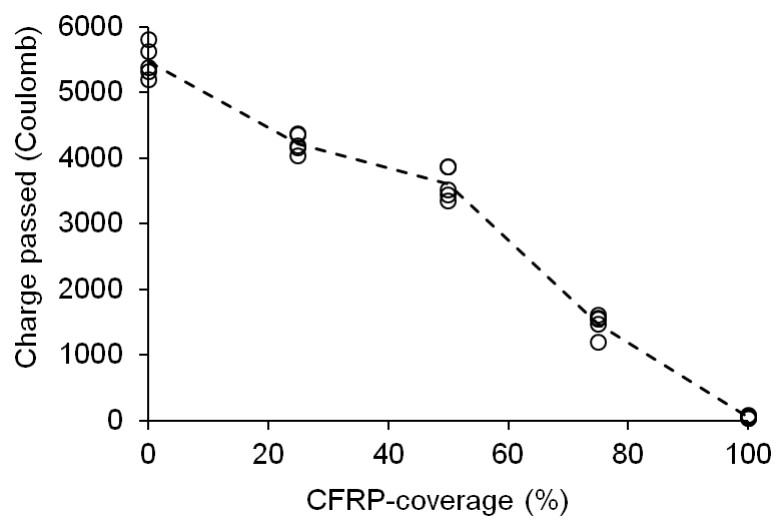

Figure 8. Charge passed

Charge passed. The charge passed of the individual specimens, representing the extent of chloride permeability, is summarized in figure 8 . The charges almost linearly decreased with an increase in CFRPcoverage with a bifurcation point at a $50 \%$ coverage ratio, which means that the transport of chlorides in the micro-pores of the concrete was affected by the degree of CFRP coverage.

\section{NEAR-FIELD MICROWAVE MICROSCOPY}

Development. Near-field microwave microscopy was developed using the scanning tunneling method (STM) to scan the chloride-impregnated concrete specimens, as shown in figure 9. The near-field microwave probe of the system stores microwave energy by applying the difference of Gaussian pulse as input through a co-axial cable. When a dielectric material such as concrete is detected near the probe tip, the reactance changes due to the permittivity and permeability of the material. A capacitive effect is accompanied to alter the electromagnetic response of the scanning object. A monopole antenna was 
employed and the length of the antenna was one-quarter of the wavelength $\lambda$. The wave generator (Waveteck 907A) shown in figure 10 transmitted microwave signals, which were magnified by a $+20 \mathrm{~dB}$ amplifier. A directional coupler was used to keep reflected signals isolated from incidental signals.

Validation and Scanning. Figure 11 shows a validation image of the developed prototype near-field microwave microscopy. The aluminum plate included six holes with a $1 \mathrm{~mm}$ notch and the scanning system detected such a geometric discontinuity. The chloride-impregnated concrete disks bonded with CFRP sheets were scanned and corresponding images are available in figure 12. The presence of the CFRP sheet was clearly detected. Additional technical interpretation on the images is currently underway to establish a relationship between the bounced microwave signals and the degree of chloride penetration in the concrete.

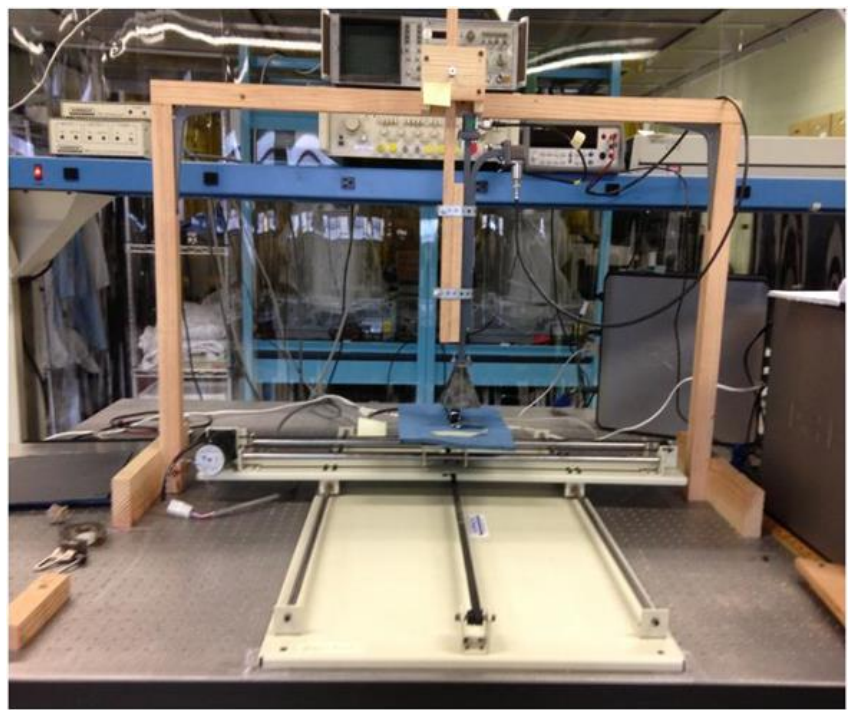

(a)

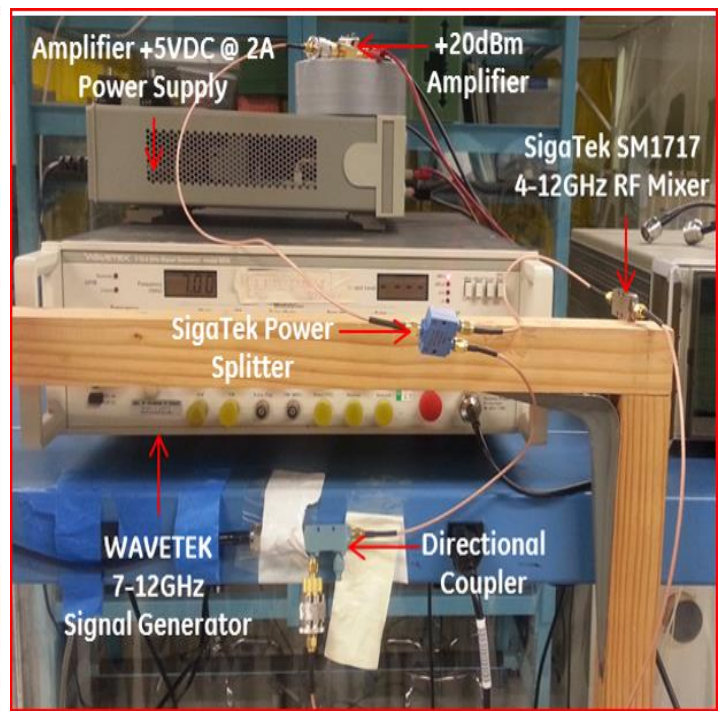

(b)

Figure 9. Prototype scanning equipment: (a) overview; (b) components

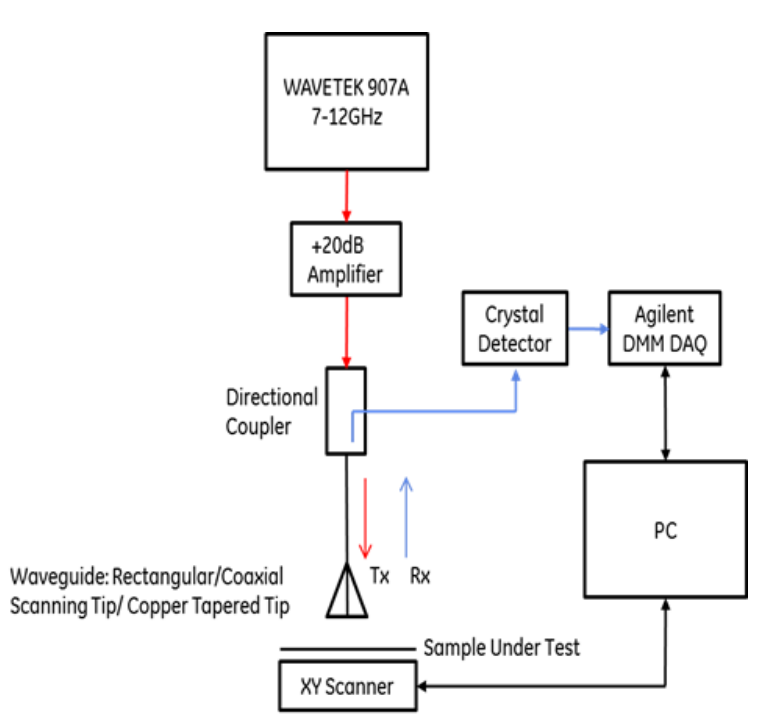

(a)

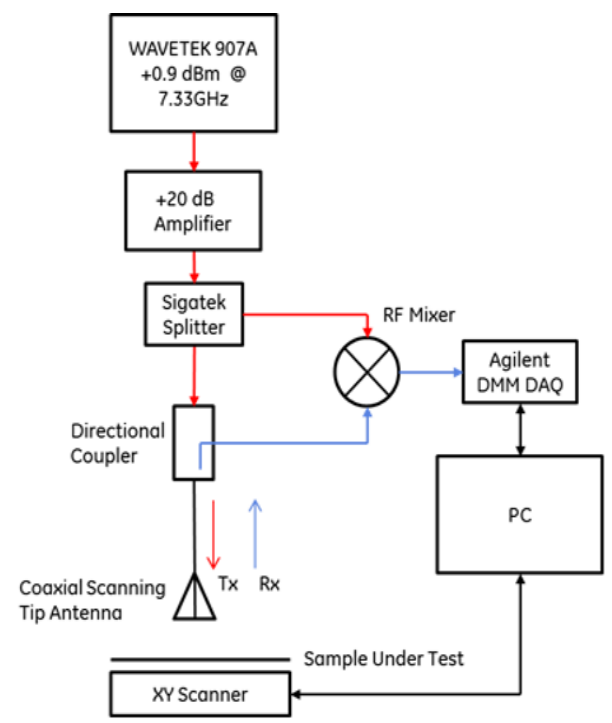

(b)

Figure 10. Detection approaches: (a) amplitude detection; (b) phase detection 


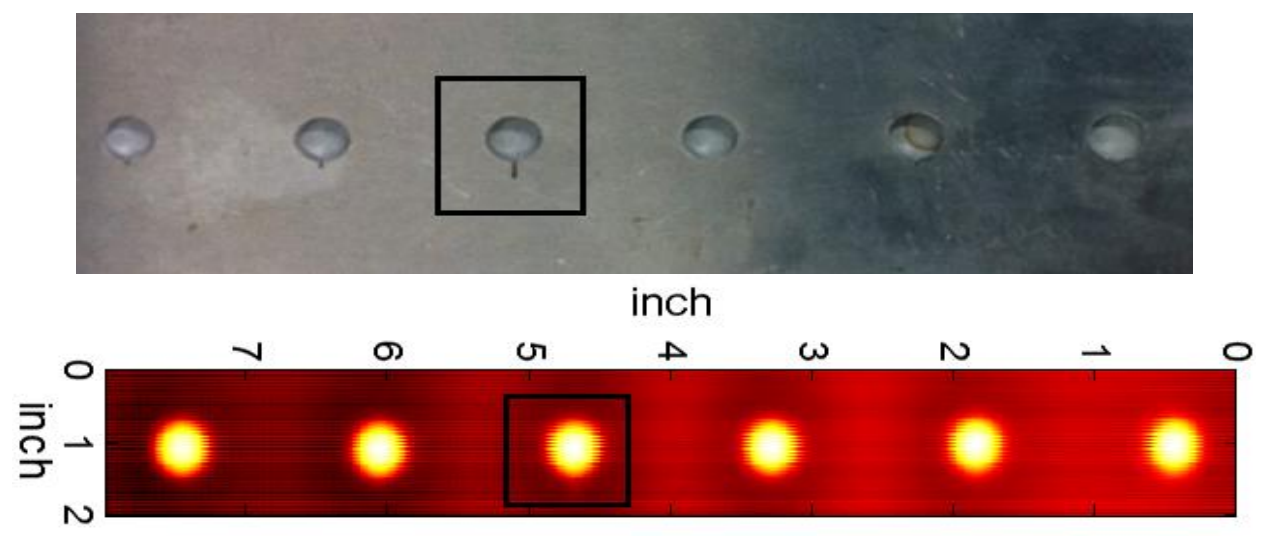

Figure 11. Validation of scanned image

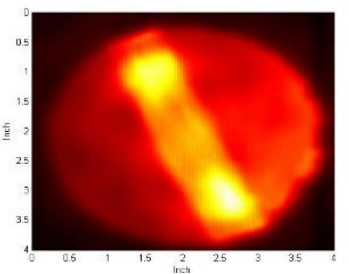

(a)

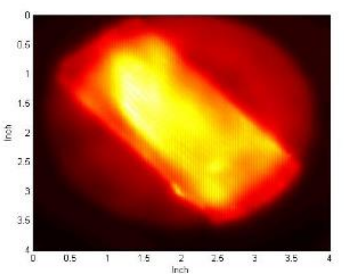

(b)

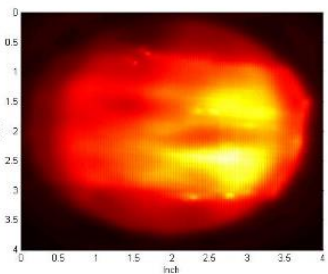

(c)

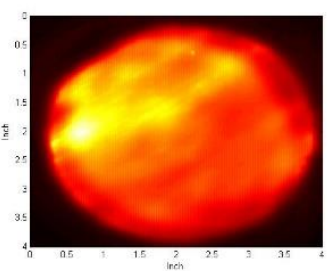

(d)

Figure 12. Scanned chloride-impregnated concrete: (a) $25 \%$ covered; (b) $50 \%$ covered; (c) $\mathbf{7 5 \%}$ covered; (d) $100 \%$ covered

\section{SUMMARY AND CONCLUSIONS}

An experimental program concerning the chloride permeability of CFRP-bonded concrete has been conducted using a test protocol suggested by ASTM C1202. Concrete disks were CFRP-covered by 0 to $100 \%$ representing uncovered and fully covered states. The likelihood of corrosion was alleviated by the CFRP sheets, while the degree of alleviation was dependent upon the extent of coverage ratios. The application of near-field microwave microscopy was examined for scanning the tested concrete. The following is concluded:

- The gradual saturation of micro-pores in the concrete was noticed due to the transport of chlorides, while the response time for the saturation was a function of the CFRP-coverage ratios. The fully covered cases completely blocked the flow of electric current.

- The thermal reactions and resistivity of the concrete were not uniform and varied with chloride exposure-time and CFRP-coverage ratios.

- The developed microwave-based sensing technique was promising to detecting the presence of the bonded CFRP and research is on-going to detect the degree of chloride ingress in the concrete specimens.

\section{ACKNOWLEDGEMENT}

The authors gratefully acknowledge financial supports from the Ministry of Higher Education in Libya and the U.S. Department of Transportation through the Mountain-Plains Consortium. 


\section{REFERENCES}

ACI (2007) Report on fiber-reinforced polymer (FRP) reinforcement for concrete structures (ACI 440R07), American Concrete Institute Committee 440, Farmington Hills, MI.

ACI (2008) Guide for the design and construction of externally bonded FRP systems for strengthening concrete structures (ACI 4402R-08), American Concrete Institute Committee 440, Farmington Hills, MI.

ASCE. 2013. Report card for America's infrastructure, American Society of Civil Engineers, Reston, VA.

ASTM (2012) Standard test method for electrical indication of concrete's ability to resist chloride ion penetration, American Society for Testing and Materials, West Conshohocken, PA.

Bentz, D.P. (2007) A virtual rapid chloride permeability test, Cement and Concrete Composites, 29, 723731.

Bousias, S.N., Triantafillou, T.C., Fardis, M.N., Spathis, L., and O'Regan, B.A. (2004) Fiber-reinforced polymer retrofitting of rectangular reinforced concrete columns with or without corrosion, ACI Structural Journal, 101(4), 512-520.

CEB (1989) Diagnosis and assessment of concrete structures: state-of-the-art report (CEB-192), Bulletin D'Information, Case Postale 88, Lausanne, Switzerland.

Kong, L. and Ge, Y. (2015) Mechanism study of effect of coarse aggregate size on permeability of concrete, ACI Materials Journal, 112(6), 797-774.

Liu, Y., Presuel-Moreno, F.J., and Paredes, M.A. (2015) Determination of chloride diffusion coefficients in concrete by electrical resistivity method, ACI Materials Journal, 112(5), 631-640.

Mohamed, A.R., El-Nadoury, W.W., and Ayyob, M.T. (2014) Generalized chloride permeability test for blended and nonblended concrete, ACI Materials Journal, 111(3), 327-333.

Soudki, K., El-Salakawy, E., and Craig, B. (2007) Behavior of CFRP strengthened reinforced concrete beams in corrosive environment, Journal of Composites for Construction, 11(3), 291-298. 